\title{
Numerical simulation of flame stabilization in meso-scale vortex combustion
}

\author{
Herman Saputro ${ }^{1}$, Heri Juwantono ${ }^{1, *}$, Husin Bugis ${ }^{1}$, Danar Susilo Wijayanto ${ }^{1}$, Laila Fitriana ${ }^{2}$, Valiant Lukad Perdana ${ }^{1}$, Aris \\ Purwanto $^{1}$, Eka Dwi Arianto ${ }^{1}$, Marshal Bima ${ }^{1}$, Yudha Pratama ${ }^{1}$, Riyadi Muslim ${ }^{1}$, and Tutuko Firdani ${ }^{1}$ \\ ${ }^{1}$ Universitas Sebelas Maret, Department of Mechanical Engineering Education, Pabelan, Surakarta, Indonesia \\ ${ }^{2}$ Universitas Sebelas Maret, Department of Mathematic Education, J1. Ir. Sutami 36A, Surakarta, Indonesia
}

\begin{abstract}
A meso-scale vortex combustor has been designed in order to common flame quenching problems in meso/micro scale burning. Numerical simulations using Computational Fluid Dynamic (CFD) Ansys Release 19.0 Academic program was performed to determine a stable combustion flame. Combustor chamber made from two steps, first step diameter $6 \mathrm{~mm}$ with $4 \mathrm{~mm}$ depth, second step diameter size $8 \mathrm{~mm}$ with $5 \mathrm{~mm}$ depth. This simulation used mixture of propane fuel-air. The fuel is fed through two channels of fuel inlet with $2 \mathrm{~mm}$ diameter. The variable of fuel flow rate was investigated in order to get the boundary of extinction limit and blow off limit of flame (stable flame region). The results show that the flame stable limit by using meso-scale vortex combustor more widely than other types of micro combustor. Therefore, the meso-scale vortex combustor that was developed could be used to overcome the flame quenching problems.
\end{abstract}

\section{Introduction}

Research on micro-meso combustion is intense developed in this decade. Micro combustion is developed for several purposes such as micro-scale drives [1-2] and micro-scale energy generation [3-10]. The need for micro-scale energy generation continues to demand growth as the development of micro technologies. Micro technology requires energy sources that have high energy density, portable, light mass, short recharge time, and long duration $[3,4,7,10]$. Micro combustion has been combined with thermoelectric generator (TEG) [3,4,6-10] Thermophotovoltaic (TPV) $[5,11,12]$ to generate electrical energy.

The general problems that occur in micro-meso combustion is the stability of flame and flame quenching. Many researchers conducted research to create flame stability and overcome flame quenching, such as the use of wire mesh as a flame holder to create flame stability $[13,14]$, the use of stepped tube micro combustion $[15,16]$ an increase in the number of steps in tubular micro combustor type increase the limits of flame stability [15], use of media porvature [17,18], and micro vortex combustion $[7,19,20]$.

Combustor vortex has advantages; flame vortex has a range of stability equivalent ratio [21]. Combustor vortex was also successfully integrated with a micro scale power plant, capable of generating a maximum energy of $8.1 \mathrm{~W}$ $(9.8 \mathrm{Vx} 0.83 \mathrm{~A})$ using a double thermoelectric device, concluding from this research that the heat transfer from flame to the combustor wall increased significantly with vortex flow, resulting in a relatively higher energy efficiency [7].
Computational Fluid Dynamic (CFD) has been widely used in engineering such as in the research [22] and to identify flame in micro combustion numerically since the 2000's [23]. CFDs are used to determine the probability of flame stability on meso-scale combustion tubes with wire mesh [14].

In this research, a meso scale combustor vortex was then analyzed in numerical simulation to determine the range of stable flame and maximum temperature that can be produced in certain velocity inlets. The fuel used is propane-air with an equivalent ratio, $\Phi=1$. The software used is Fluet Ansys Release 19.0 Academic version.

\section{Numerical Model Descriptions}

\subsection{Combustor Design}

The meso scale vortex combustor design concept can be seen as in fig. 1 . fuel goes through inlet 1 and inlet 2 with a diameter of $2 \mathrm{~mm}$. Combustion area consists of one-step tube with mixing area diameter $6 \mathrm{~mm}$ and depth $4 \mathrm{~mm}$, and flame area with diameter $8 \mathrm{~mm}$ with depth $9 \mathrm{~mm}$.

\footnotetext{
* Corresponding author: hermansaputro@staff.uns.ac.id
} 


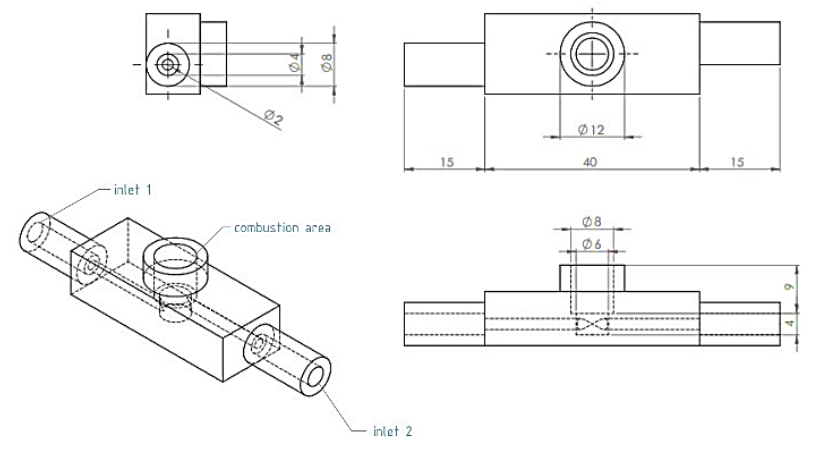

Fig. 1. meso scale vortex combustor design.

\subsection{CFD Simulation}

\subsubsection{Meshing}

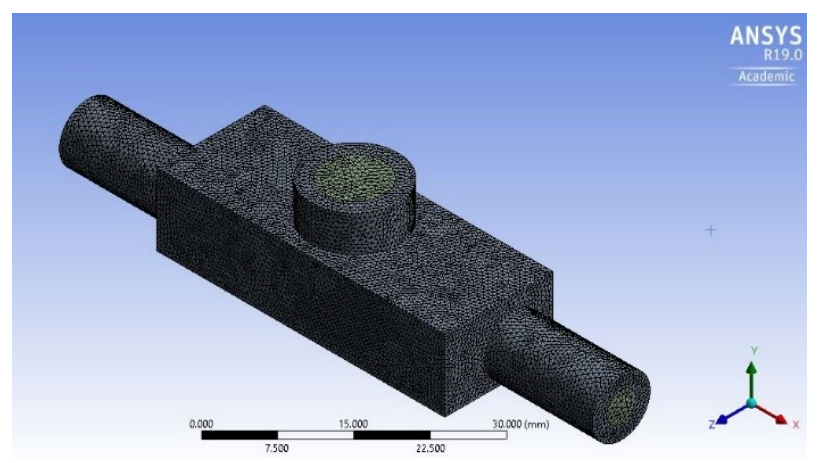

Fig. 2. Meshing meso scale vortex combustor.

The mesing method uses the element size the total number of elements is 496929 cells. The results of the meshing process can be seen in fig. 2 .

\subsubsection{CFD Setting}

The fuel used in the meso vortex combustor is propane (C3H8) - air, where the equivalent ratio of air degan fuel is set at 1 . The propane air fraction with air is as follows: It is assumed that the air composition is $78 \% \mathrm{~N} 2$, and $21 \%$ $\mathrm{O} 2$.

$$
\begin{gathered}
C_{x} \mathrm{H}_{y}+a\left(\mathrm{O}_{2}+3.76 \mathrm{~N}_{2}\right) \rightarrow x \mathrm{CO}_{2}+\frac{y}{2} \mathrm{H}_{2} \mathrm{O}+3.76 a \mathrm{~N}_{2} \\
\mathrm{C}_{3} \mathrm{H}_{8}+a\left(\mathrm{O}_{2}+3.76 \mathrm{~N}_{2}\right) \rightarrow 3 \mathrm{CO}_{2}+4 \mathrm{H}_{2} \mathrm{O}+3.76 a \mathrm{~N}_{2} \\
a=\frac{x+\frac{y}{4}}{\Phi}=\frac{3+2}{1.0}=5 \\
\mathrm{C}_{3} \mathrm{H}_{8}+5\left(\mathrm{O}_{2}+3.76 \mathrm{~N}_{2}\right) \rightarrow 3 \mathrm{CO}_{2}+4 \mathrm{H}_{2} \mathrm{O}+18.8 \mathrm{~N}_{2}
\end{gathered}
$$

Finding the molar fraction $(\chi)$ of each species;

$$
\begin{gathered}
N_{C_{3} H_{8}}=1 ; \chi_{C_{3} H_{8}}=\frac{N_{C_{3} H_{8}}}{N_{\text {Total }}}=\frac{1}{1+5+18.8}=\frac{1}{24.8} \\
=0.040323 \\
N_{O_{2}}=5 ; \chi_{O_{2}}=\frac{N_{O_{2}}}{N_{\text {Total }}}=\frac{5}{1+5+18.8}=\frac{5}{24.8}=0.20162
\end{gathered}
$$

$$
N_{N_{2}}=18.8 ; \chi_{N_{2}}=\frac{N_{N_{2}}}{N_{\text {Total }}}=\frac{18.8}{1+5+18.8}=\frac{18.8}{24.8}=0.7580
$$

Calculating the mix molecular weight $\left(M W_{\text {mix }}\right)$

$$
\begin{gathered}
M W_{\text {mix }}=\sum \chi_{i} M W_{i} ; \\
M W_{\text {mix }}=\chi_{C_{3} H_{8}} M W_{C_{3} H_{8}}+\chi_{O_{2}} M W_{O_{2}}+\chi_{N_{2}} M W_{N_{2}} \\
M W_{\text {mix }}=0.040323(44.06)+0.20162(32)+ \\
0.7580(28.013) ; \\
M W_{\text {mix }}=1.7763138+6.45184+21.233854 \\
M W_{\text {mix }}=29.4620 \frac{\mathrm{kg}}{\mathrm{kmole}} ;
\end{gathered}
$$

Thus, the species mass fraction for $\mathrm{C}_{3} \mathrm{H}_{8}$ and $\mathrm{O}_{2}$ can be determined by;

$$
\begin{gathered}
Y_{C_{3} H_{8}}=\frac{\chi_{C_{3} H_{8}} M W_{C_{3} H_{8}}}{M W_{\text {mix }}}=\frac{1.7763}{29.4620}=0.060291 \\
Y_{O_{2}}=\frac{\chi_{O_{2}} M W_{O_{2}}}{M W_{\text {mix }}}=\frac{6.45184}{29.4620}=0.21898
\end{gathered}
$$

From the results of the above mass fraction is used as input data on Ansys Fluent.

For solver used pressure-based type, absolute velocity formula, steady time. The model setup is used energy on mode, $\mathrm{k}-\varepsilon$ standard viscosity, transport and reaction species using internal fluent data settings for propane-air and pre-calculated mass fraction input.

Material is assumed to use aluminum material with thermal conductivty 273 (W /m.K). To power the propane-water mixture, patching is done on the $1 \mathrm{~mm}$ end of the combustion area of the combustion area output [24], which is set at $1800 \mathrm{~K}$. Velocity inlet varies from $0.01 \mathrm{~m} / \mathrm{s}$ until a blow-out limit of flame is found in the combustor, or until a flame stability area is found. From the results of stable flame computing is determined the highest output temperature, which inlet velocity is produced the highest thermal energy. Residual setting uses the default setting of fluent, which will achieve convergence at $10^{-6}$ for energy and $10^{-3}$ for other residuals.

\section{Result and Discussion}

The simulation starts with inet velocity $0.01 \mathrm{~m} / \mathrm{s}$ until the blow out limit of the flame is obtained. To ensure mixture flowing vortex in the combustion area can be seen in fig.3. The vortex flow in the combustion area with inlet velocity $0.01 \mathrm{~m} / \mathrm{s}$.

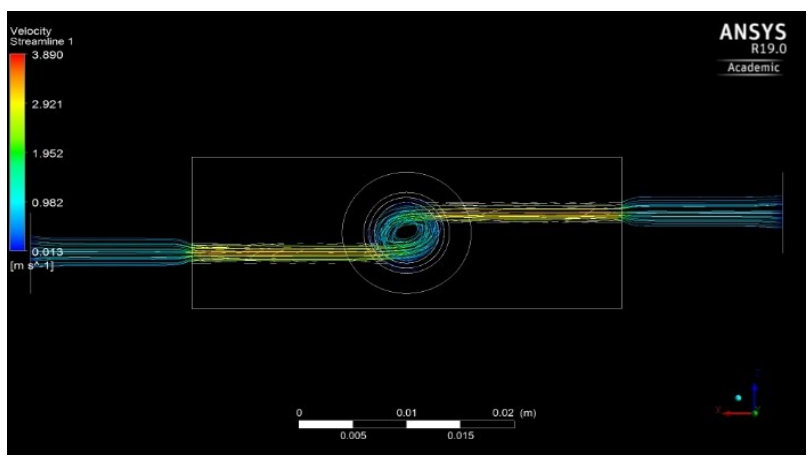

Fig. 3. Vortex flow at $u=0.01 \mathrm{~m} / \mathrm{s}$. 
Computational results show flame stability on meso scale combustor is obtained at inlet velocity below 4.0 $\mathrm{m} / \mathrm{s}$. YZ plane in the center of the combustion area is made to take a sample of contour term on each velocity inlet. the appearance of the resulting temperature contour on each inlet velocity with $\Phi=1$ can be seen in fig. 4-fig. 13 .

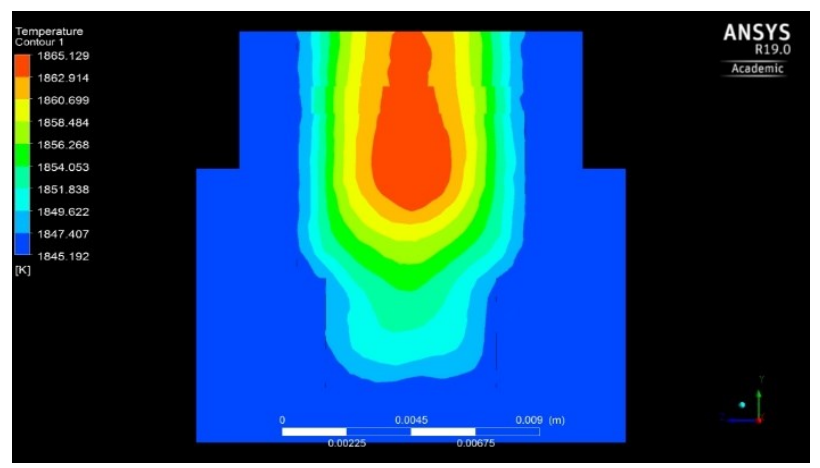

Fig. 4. Temperature Contour at $\mathrm{u}=0.01 \mathrm{~m} / \mathrm{s}$.

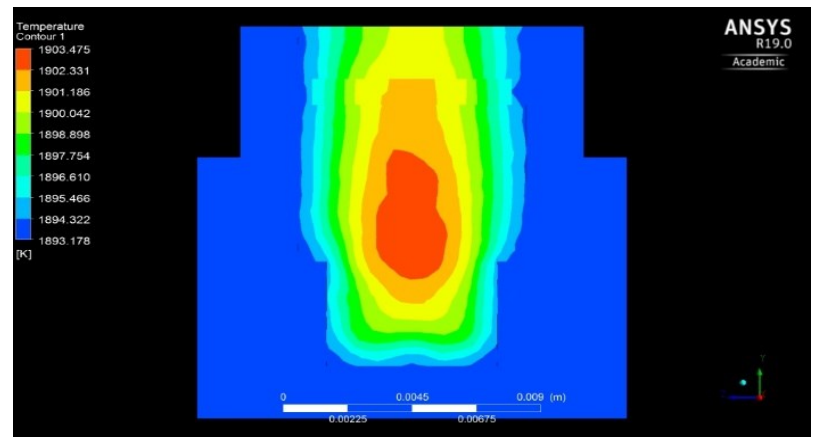

Fig. 5. Temperature Contour at $\mathrm{u}=0.03 \mathrm{~m} / \mathrm{s}$.

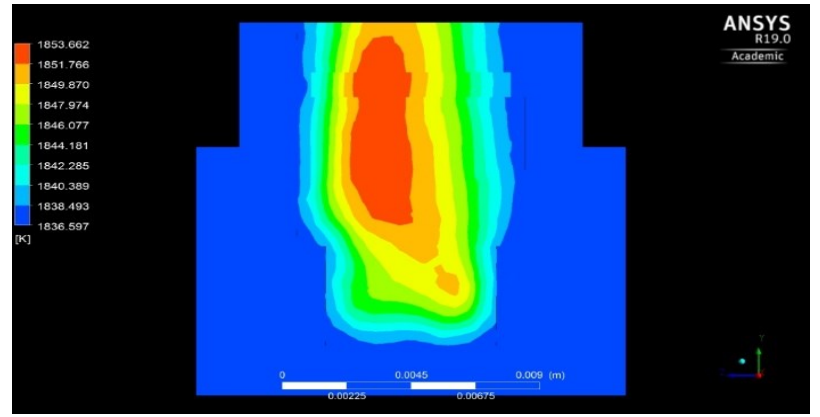

Fig. 6. Temperature Contour at $\mathrm{u}=0.05 \mathrm{~m} / \mathrm{s}$.

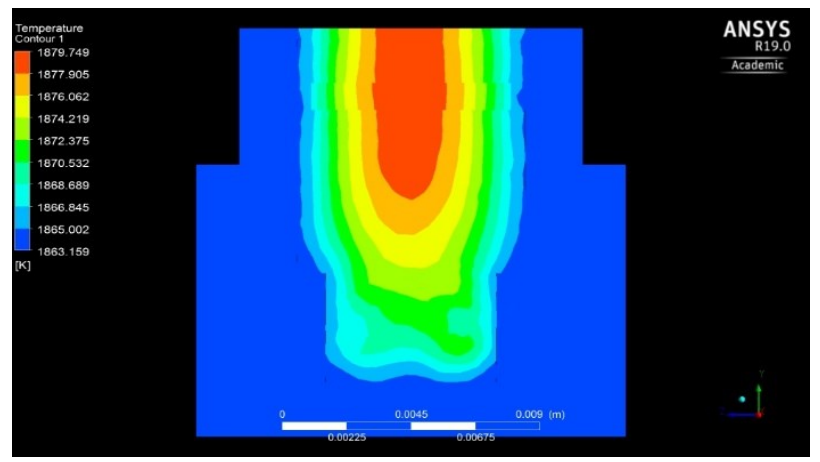

Fig. 7. Temperature Contour at $u=0.1 \mathrm{~m} / \mathrm{s}$.

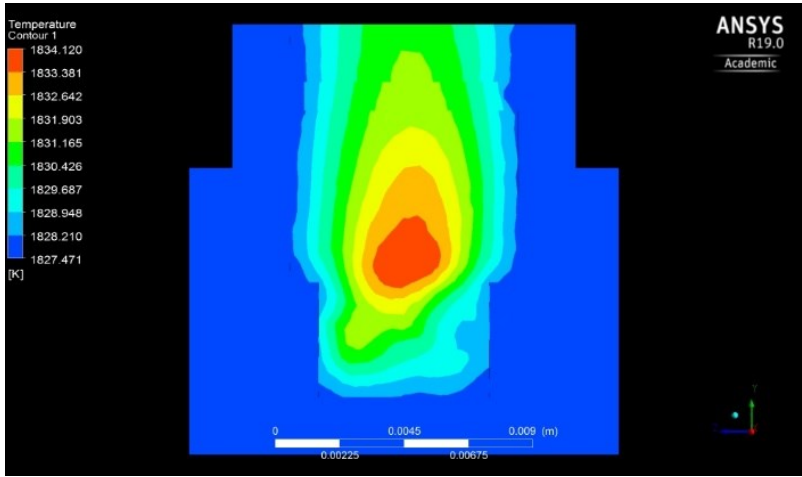

Fig. 8. Temperature Contour at $\mathrm{u}=0.15 \mathrm{~m} / \mathrm{s}$.

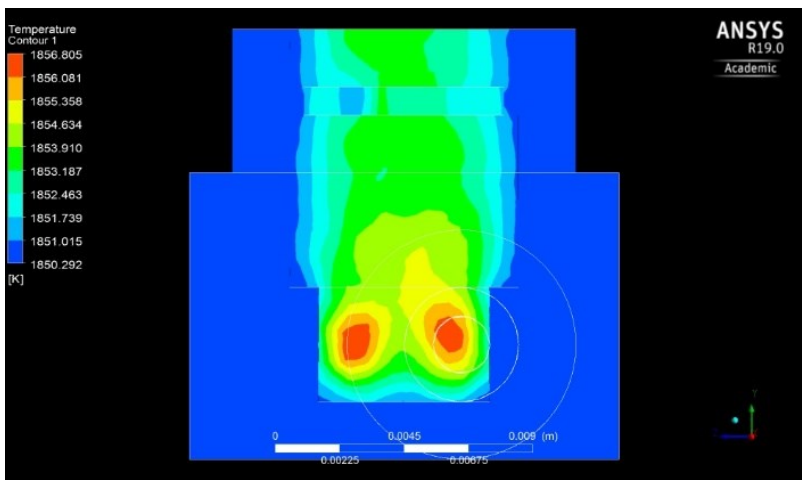

Fig. 9. Temperature Contour at $\mathrm{u}=0.2 \mathrm{~m} / \mathrm{s}$.

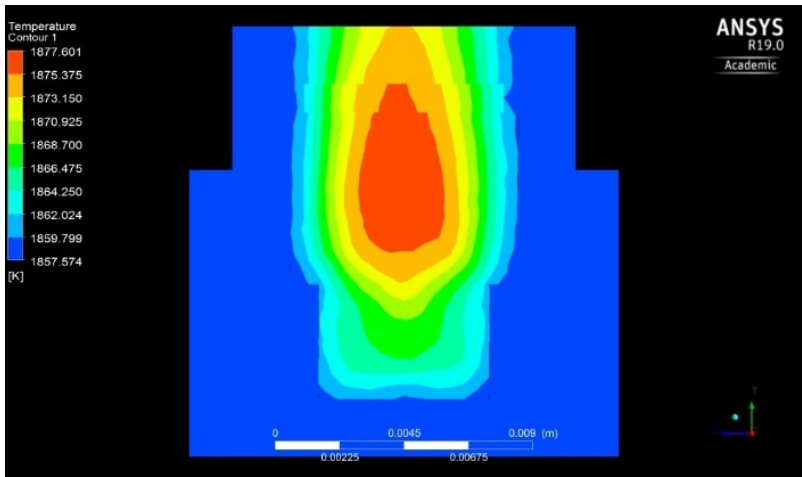

Fig. 10. Temperature Contour at $u=0.25 \mathrm{~m} / \mathrm{s}$.

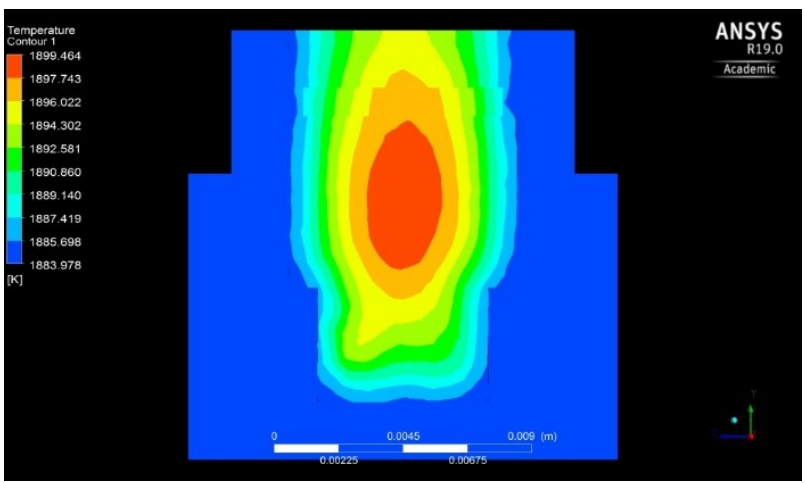

Fig. 11. Temperature Contour at $u=0.3 \mathrm{~m} / \mathrm{s}$. 


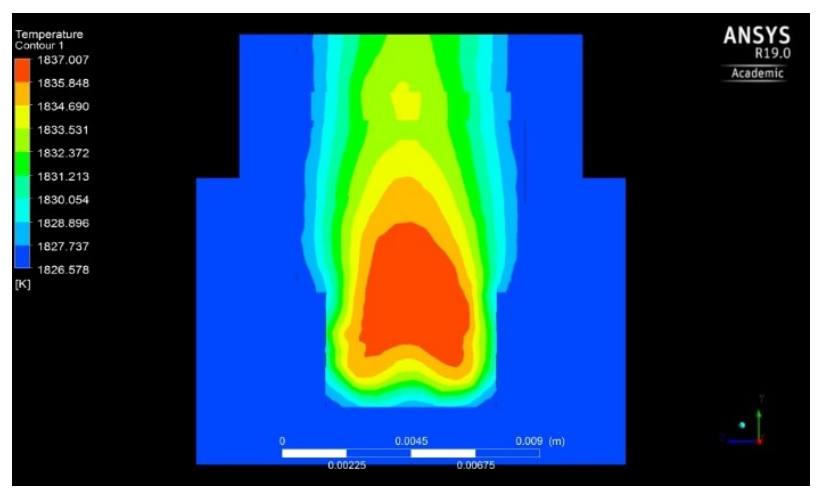

Fig. 12. Temperature Contour at $u=0.35 \mathrm{~m} / \mathrm{s}$.

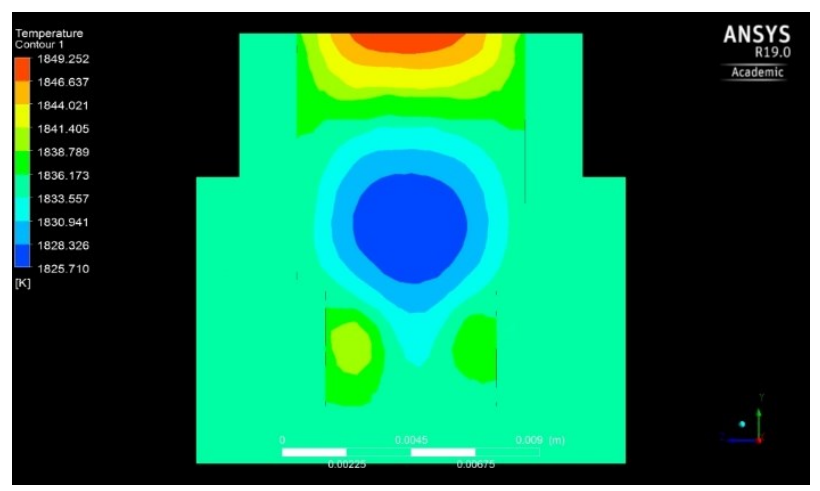

Fig. 13. Temperature Contour at $\mathrm{u}=0.4 \mathrm{~m} / \mathrm{s}$.

From that temperature contours it is found that flame stability of meso combustor is below $\mathrm{u}=0.4 \mathrm{~m} / \mathrm{s}$, and from each variation of inlet velocity is obtained temperature range, which can be seen in table 1 .

Table 1. Output range temperature each inlet velocity at $\Phi=1$.

\begin{tabular}{|c|c|c|}
\hline $\mathbf{U}$ (m/s) & Low temp (K) & High temp. (K) \\
\hline 0.01 & 1845.192 & 1865.169 \\
\hline 0.03 & 1893.178 & 1903.475 \\
\hline 0.05 & 1836.597 & 1853.662 \\
\hline 0.1 & 1863.159 & 1879.749 \\
\hline 0.15 & 1827.471 & 1834.12 \\
\hline 0.2 & 1850.292 & 1856.805 \\
\hline 0.25 & 1857.574 & 1877.601 \\
\hline 0.3 & 1883.978 & 1899.464 \\
\hline 0.35 & 1826.578 & 1837.007 \\
\hline 0.4 & 1825.71 & 1849.252 \\
\hline
\end{tabular}

Based on temperature it can be determined that the largest thermal energy which can be produced by this meso vortex combustor with the propane-water fuel $\Phi=$ 1 is in the velocity inlet $0.03 \mathrm{~m} / \mathrm{s}$ which can produce lower temperature $1893.178 \mathrm{~K}$ and higher temperature 1903.475 $\mathrm{K}$. graphically can be seen in fig. 14 .

\section{Output Temp. Meso Vortex Combustion}

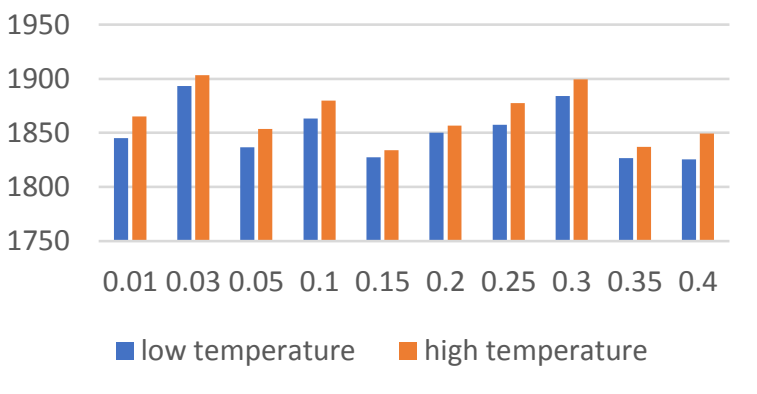

Fig. 14. Meso-scale vortex combustion temperatur output graph.

\section{Conclusion}

Based on the numerical simulation of meso scale vortex combustion that has been done. Computational results show that with propane air mixture fuel and with equivalent ratio $=1$, the stability area of flame in the velocity inlet is below $4.0 \mathrm{~m} / \mathrm{s}$. The highest output temperature was reached at $0.03 \mathrm{~m} / \mathrm{s}$ inlet velocity with the highest output temperature reaching 1903,475 K. For experimental purposes, the result of the output temperature should be used material other than aluminum which has higher melting point than the temperature for experimental purposes.

This research was partly subsidized by Grant of Penelitian Unggulan (PU-UNS) research PNPB Universitas Sebelas Maret 2018. The researchers gratefully acknowledge financial support from the LPPM Universitas Sebelas Maret, Surakarta, Indonesia.

\section{References}

1. C. Rossi, T. Do Conto, D. Esteve, B. Larangot, Smart Mater. Struct. 10 (6) 1156-1162. (2001)

2. G. Saravanan, C. Suresh, Numerical Simulation of Mixing. Procedia Engineering 38, 3969-3976, (2012)

3. B. Aravind, G.K.S. Raghuram, V. Ratna Kishore, S. Kumar, Compact Design of Planar. Energy Conversion and Management 156, 224-234. (2018)

4. L. Meng, J. Li, Q. Li, A miniaturized Power Gen. International Journal of Hydrogen Energy 42, 17275-17283. (2017)

5. W. M. Yang, S. K. Chou, C. Shu, Z. W. Li, and H. Xue, Development of Microthermophotovoltanic. Aplied Physics Letter. 81, 5255 (2002)

6. S. Yadav, P. Yamasani, and S. Kumar, Experimental studies on a. Energy Conversion and Management. 99, 1-7. (2015)

7. D. Shimokuri, T. Hara, and R. Matsumoto, Development of a Small. J. Micromech. Microeng. 25 (2015)

8. D. C. Kyritsis, B. Coriton, F. Faure, S. Roychoudhury, and A. Gomez. Optimalization of a catalytic. Combustion and Flame 139, 77-89. (2004) 
9. C. Fanciulli, H. Abedi, L. Merotto, R. Donde, S. D. Iuliis, and F. Passaretti, Portable Thermoelectric Power. Aplied Energy. 215. 300-308. (2018)

10. L. Merotto, C. Fanciulli, R. Donde, and S. D. Iulliis, Study of a thermoelectric. Aplied Energy. 162, 346353. (2016)

11. J.Li, S.K. Chou, Z.W. Li, W.M. Yang, A Potential heat source for. Chem. Eng. Science. 64, 3282-3289. (2009)

12. L.C. Chia, and B. Feng, The development of a micropower. Journal of Power Sources. 165, 455480. (2007)

13. M. Mikami, Y. Maeda, K. Matsui, T. Seo, and L. Yuliati, Combustion of Gaseous and Liq. Procceedings of Combustion Institute. 34, 33873394. (2013)

14. F. A. Munir, and M. Mikami, Modeling of Propaneair. $10^{\text {th }}$ ASPACC

15. B. Khandelwal, A. A. Deshpande, and S. Kumar, Experimental studies on flame. Applied Thermal Eng. 58, 363-368. (2013)

16. A. A. Deshpande, and S. Kumar, On the Formation of Spinning Flames. Appl. Thermal Eng. 51, 91-101. (2013)

17. J. Li, S.K. Chou, Z.W. Li, and W.M. Yang, Experimental Investigation of Porus. Fuel. 89, 708715. (2010)

18. J. Li, Y. Wang, J. Chen, J. Shi, and X. Liu, Experimental Study on Standing Wave. Fuel. 167, 98-105. (2016)

19. M. Khaelghi, S.E. Hosseini, and M.A. Wahid, Investigation of Asymetric non-premixed. Applied Thermal Eng. 81, 140-153. (2015)

20. M. Wu, Y. Wang, V. Yang, and R.A. Yetter, Combustion in meso-scale vortex chambers. Procc. Of the Combustion Institute. 31, 3235-3242. (2007)

21. Ishizuka S, and D. Rankin, Turbular Combustion. Sust. Energy, (New York : Momentum press, 2013)

22. H. Saputro et al., "The CFD Simulation of Cyclone Separator without and with the Counter-cone in the Gasification Process," IOP Conf. Ser. Mater. Sci. Eng., (2018)

23. S. Raimondeau, D. Norton, D.G. Vlachos, and R.I. Masel, Modeling of High Temperature. Proceedings of the Combustion Institute, 29 (2002)

24. F.A. Munir, M. Mikami, M.Z. Hassan, and M.A. Salim, Flame stabilition in multiple inlet. Journal of Advanced Vehicle System. 4 Issue 1, 20-27. (2017) 